\title{
Development of an Analytical Method for Determination of Nitrate in Leafy Vegetables Using Ion Chromatography
}

\author{
Douglas Gonçalves da Silva ${ }^{*}$, Anaildes Lago de Carvalho ${ }^{1}$, Evanildo de Jesus Araújoㄹ, \\ Marcelo Eça Rocha ${ }^{1}$, Bruno Oliveira Moreira ${ }^{2}$, Dhavid Lucas Silva Santos ${ }^{3}$
}

\author{
${ }^{1}$ Analytical Chemistry Laboratory, State University of Southwest Bahia, Vitória da Conquista, Bahia, Brazil \\ ${ }^{2}$ Federal Universityof Bahia, Campus Anísio Teixeira, Vitória da Conquista, Bahia, Brazil \\ ${ }^{3}$ University Center UniFTC, Vitória da Conquista, Bahia, Brazil \\ Email: *douglasquimico@hotmail.com
}

\begin{abstract}
How to cite this paper: da Silva, D.G., de Carvalho, A.L., Araújo, E. de J., Rocha, M.E., Moreira, B.O. and Santos, D.L.S. (2020) Development of an Analytical Method for Determination of Nitrate in Leafy Vegetables Using Ion Chromatography. Open Access Library Journal, 7: e6471.

https://doi.org/10.4236/oalib.1106471
\end{abstract}

Received: May 27, 2020

Accepted: June 12, 2020

Published: June 15, 2020

Copyright (๑) 2020 by author(s) and Open Access Library Inc.

This work is licensed under the Creative Commons Attribution International License (CC BY 4.0).

http://creativecommons.org/licenses/by/4.0/

\begin{abstract}
The presence of nitrate in food in general may indicate a threat to human health. Nitrate can be converted to nitrite, a toxic species, in saliva and in the gastrointestinal tract. This work describes a precise and sensitive method using ion chromatography to determine nitrate $\left(\mathrm{NO}_{3}^{-}\right)$in hardwood vegetables. In the proposed method the extraction of the nitrate of the vegetal matrix was carried out in an aqueous medium at a temperature of $70^{\circ} \mathrm{C}$. The limit of detection (LOD) for the determined ion was $0.06 \mu \mathrm{g} \cdot \mathrm{L}^{-1}$. The accuracy of the method was evaluated as the relative standard deviation (DPR) of the analytical signal area and the retention time, with values of $0.63 \%$ and $0.41 \%$, respectively, for a solution of $\mathrm{NO}_{3}^{-} 5.0 \mathrm{mg} \cdot \mathrm{L}^{-1}$. The detector presented linearity between 0.22 and $10 \mathrm{mg} \cdot \mathrm{L}^{-1}$ with a correlation coefficient of 0.9999 . The accuracy of the procedure was evaluated by addition/recovery test using real samples in which values greater than $95 \%$ were obtained. The validation of the proposed method was also performed by comparing the $\mathrm{NO}_{3}^{-}$concentrations obtained using the selective ion electrode method (EIS). The paired Student $t$ test and the $\mathrm{F}$ test showed that both methods provide equivalent results concerning accuracy and precision.
\end{abstract}

\section{Subject Areas}

Analytical Chemistry

\section{Keywords}

Vegetables, Chemical Analysis, Nitrate, Ion Chromatography 


\section{Introduction}

Nitrates are nitrogenous compounds present in abundance in nature. They are found in soil, water, and plants, and are therefore distributed in the food of animal and vegetable origin. They are also used as food additives, in the forms of sodium and potassium salts [1]. Among the foods with the highest concentrations of nitrate are vegetables such as fruits and vegetables, representing around $44 \%$ to $72 \%$ of the daily intake of nitrate [2]. In vegetables, especially hardwood, nitrate plays a crucial role in the growth and yield of harvested products.

In Brazil, conventional agriculture is characterized by the mechanization and high use of fertilizers, herbicides and insecticides and nitrogenous chemical fertilizer, leading to the supply of nitrate directly to the plants. An adequate supply of nitrogen is associated with high photosynthetic activity and vigorous vegetative growth [3]. Lettuce, cauliflower, spinach and arugula are leafy vegetables rich in vitamin $\mathrm{A}$, lutein, vitamins $\mathrm{B} 2, \mathrm{~B} 5, \mathrm{~B} 9, \mathrm{C}, \mathrm{K}$, calcium, iron, magnesium and potassium [4]. The main properties of these vegetables are to help in the growth, in the maintenance of skin, bones, hair and vision. The digestive, nervous, immune and sexual systems are also benefited by these vegetables, which still reduce cholesterol and the risk of cardiovascular diseases [5].

The main risks associated with the ingestion of food of plant origin contaminated with high concentrations of nitrate are its endogenous reduction to nitrite and the production of methemoglobinemia. The nitrite in the bloodstream oxidizes the hemoglobin iron, producing methemoglobin [6].

Several methods, described in the literature, are used for the determination of nitrates in plant material, including colorimetry [7], flow injection analysis with colorimetric detection [8], potentiometry [9], polarography [10]. Separation methods include capillary electrophoresis [11] [12] [13] and ion chromatography [14]. Ion chromatography, since its introduction in the mid-1970s [15], has been a useful tool for the determination of ionic species in a fast and adequate way.

In the light of the above, the paper proposes to develop a simple and sensitive method for the determination of nitrate in hardwood vegetables of popular culture (lettuce, cauliflower, spinach, and rocket) acquired in different municipalities of the state of Bahia-Brazil using the ion chromatography.

\section{Material and Methods}

\subsection{Reagents}

In this study, all the reagents used were of a high analytical grade. Aqueous solutions were prepared with deionized water, ultrapure (resistivity $18.2 \mathrm{M} \Omega \mathrm{cm}$ ), obtained from a Milli-Q system (Millipore, Bedford, MA, USA). For the determinations, a standard stock solution of $\mathrm{NO}_{3}^{-} 50 \mathrm{mg} \cdot \mathrm{L}^{-1}$ was prepared from a P.A. Vetec salt. Solutions of $\mathrm{Na}_{2} \mathrm{CO}_{3} 5.4 \mathrm{mmol} \cdot \mathrm{L}^{-1}$ and $\mathrm{NaHCO}_{3} 5.1 \mathrm{mmol} \cdot \mathrm{L}^{-1}$ were prepared by weighing suitable batches of the respective P.A. Vetec salts. 


\subsection{Instrumentation}

For the determination of nitrate $\left(\mathrm{NO}_{3}^{-}\right)$, a METROHN ion chromatograph (Herisau, Switzerland), model 883 Basic IC plus, composed of a high-pressure pump (Ipump), a conductivity detector with controlled detection stabilizer by a MagIC Net Basic software and a "packed bed" chemical suppression system. Separation of the analyte was performed using a Metrohn mark high-resolution anion column (model METROSEP A Supp4-250/4.0).

The volume of the sample injected was $20 \mu \mathrm{L}$, which was subjected to isocratic elution, whose mobile phase is composed of $\mathrm{Na}_{2} \mathrm{CO}_{3} 5.4 \mathrm{mmol} \cdot \mathrm{L}^{-1}$ and $\mathrm{NaHCO}_{3}$ $5.1 \mathrm{mmol} \cdot \mathrm{L}^{-1}$. A solution of $100 \mathrm{mmol} \cdot \mathrm{L}^{-1} \mathrm{H}_{2} \mathrm{SO}_{4}$ was employed as an anion exchange resin regenerator of the conductivity chemical suppression system. Data was acquired using MagICNet software installed on a computer.

\subsection{Calibration}

The calibration curve was constructed by plotting the peak areas versus the concentrations of the injected standards. Injections were performed in triplicate at six levels, ranging from 0.1 to $10.0 \mathrm{mg} \cdot \mathrm{L}^{-1}$.

\subsection{Collection, Storage, and Preparation of Samples}

Samples of lettuce, cabbage, spinach, and arugula, of conventional cultivars, were obtained from free markets in different cities of the state of Bahia: Vitória da Conquista, Jequié, and Poções. Three (03) different lots were collected for each vegetable between January and February of 2020. Each lot was analyzed in triplicate for a total of 108 samples.

After collection, the samples were stored in closed and refrigerated bags to avoid the proliferation of fungi and bacteria. The vegetables were washed in running water to remove sand particles and then ground in a 1:1 (w/w) deionized water blender until a homogeneous mass was obtained.

\subsection{Extraction of $\mathrm{NO}_{3}^{-}$with an Aqueous Solution}

Extraction of $\mathrm{NO}_{3}^{-}$from the vegetable matrix was performed in an aqueous medium at a temperature of $70^{\circ} \mathrm{C}$. To this end, $2000 \pm 0.001 \mathrm{~g}$ of each vegetable sample was added in $40 \mathrm{~mL}$ of deionized water preheated to $70^{\circ} \mathrm{C}$. The samples were kept in a water bath for 15 minutes. The extract was then transferred to a $100 \mathrm{~mL}$ volumetric flask which had its volume filled with deionized water. Subsequently, the suspensions were filtered on qualitative Whatman filter paper and stored in capped polyethylene bottles for the determinations. Samples were injected into the ion chromatograph using a standard needleless syringe, after being filtered again with a $0.45 \mu \mathrm{m}$ nylon filter, MillexR-HN type (Millipore, Beadford, MA, USA).

\section{Results and Discussion}

Figure 1 shows the chromatogram of the standard solution of $\mathrm{NO}_{3}^{-} 5.0 \mathrm{mg} \cdot \mathrm{L}^{-1}$. 


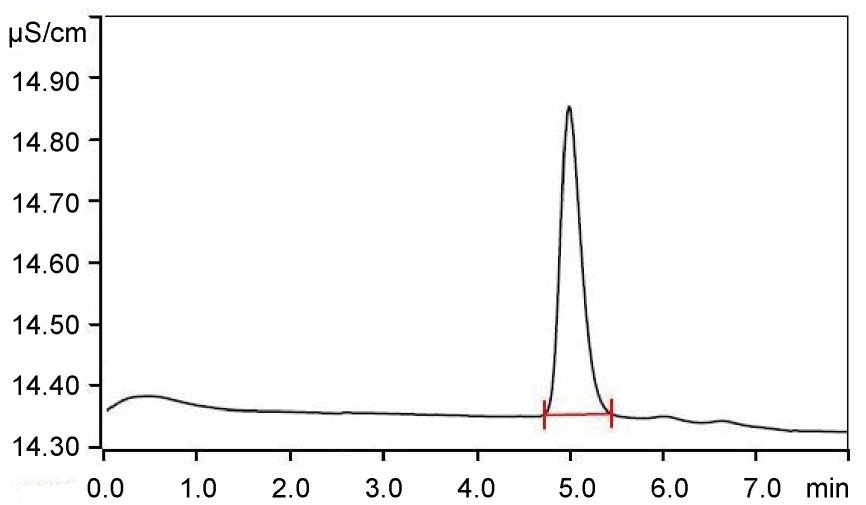

Figure 1. Chromatogram of $\mathrm{NO}_{3}^{-}$in reference standard solution 5.0 $\mathrm{mg} \cdot \mathrm{L}^{-1}$.

Under the chromatographic conditions imposed, the retention time of the standard solutions was about 5 minutes with an analysis time of 8 minutes. The retention time was observed to decrease slightly with increasing $\mathrm{NO}_{3}^{-}$concentration.

The calibration curve was constructed using external standardization from six points of the standard $\mathrm{NO}_{3}^{-}$solutions at concentrations between 0.1 and 10.0 $\mathrm{mg} \cdot \mathrm{L}^{-1}$.

The linear regression equation obtained was $\mathrm{A}=0.06715\left[\mathrm{NO}_{3}^{-}\right]-0.00538, \mathrm{R}$ $=0.9999$, where $\mathrm{A}$ is the peak area of the chromatogram for the determined analyte, $\left[\mathrm{NO}_{3}^{-}\right]$is the concentration $\left(\mathrm{mg} \cdot \mathrm{L}^{-1}\right)$ of nitrate ions er and is the correlation ratio.

The limit of detection ( $\mathrm{LOD}, \mathrm{S} / \mathrm{N}=3$ ) of $\mathrm{NO}_{3}^{-}$was $0.06 \mathrm{mg} \cdot \mathrm{L}^{-1}$, equivalent to $0.03 \mathrm{mg} \cdot \mathrm{g}^{-1}$, while the limit of quantification (LOQ) was $0.22 \mathrm{mg} \cdot \mathrm{L}^{-1}(0.11$ $\left.\mathrm{mg} \cdot \mathrm{g}^{-1}\right)$. The linear range of work for the operating method ranged from 0.22 $\mathrm{mg} \cdot \mathrm{L}^{-1}$ to $10 \mathrm{mg} \cdot \mathrm{L}^{-1}$ of $\mathrm{NO}_{3}^{-}$in vegetable samples.

In a chromatographic analysis, it is essential to know the retention time repeatability (tR) and the area of the analytical signal or peak height. According to Lances, the repeatability of the retention time is important because, in most chromatographic analyzes, it is used to confirm the identity of the compound (qualitative analysis), and the repeatability of the area (or height) of the analytical signal is important because it is the parameter used in the quantification of the compound of interest (quantitative analysis) [16]. ANVISA suggests a minimum of six determinations for repeatability to be verified [17]. Thus, the repeatability of the method was verified by injecting (six times) the same standard solution of nitrate in succession.

The relative standard deviation (DPR) of the analytical signal area and the retention time for $\mathrm{NO}_{3}^{-}(\mathrm{n}=6)$ was $0.63 \%$ and $0.41 \%$, respectively, for a standard solution of $\mathrm{NO}_{3}^{-} 5 \mathrm{mg} \cdot \mathrm{L}^{-1}$. According to these data, the method employed has good accuracy.

The assessment of method accuracy was based on addition/recovery assays. The tests were performed comparing the results obtained in the determination 
of $\mathrm{NO}_{3}^{-}$in the real samples with the results obtained when determining the ion in the samples containing a known concentration of the standard solution of $\mathrm{NO}_{3}^{-}$. The results are shown in Table 1 .

Recoveries in the range of 94.0 and $116.0 \%$ were obtained by the proposed method, indicating the absence of matrix effects.

Table 2 shows the concentrations of $\mathrm{NO}_{3}^{-}$found in different leafy vegetables and determined by ion chromatography.

In Brazil, there is no specific legislation regulating maximum limits or acceptable daily intake for nitrates in foods of plant origin. Therefore, according to

Table 1. Evaluation of the accuracy through the recoveries obtained for $\mathrm{NO}_{3}^{-}$in lettuce samples.

\begin{tabular}{|c|c|c|c|}
\hline \multirow{2}{*}{ Sample } & \multicolumn{2}{|c|}{ Amount of $\mathrm{NO}_{3}^{-}\left(\mathrm{mg} \cdot \mathrm{L}^{-1}\right)$} & \multirow{2}{*}{ Recovery (\%) } \\
\hline & Added & Found & \\
\hline \multirow{3}{*}{ Lettuce } & 0.0 & $<\mathrm{LQ}$ & - \\
\hline & 5.0 & 5.4 & 108.0 \\
\hline & 10.0 & 11.5 & 115.0 \\
\hline \multirow{3}{*}{ Cauliflower } & 0.0 & $<\mathrm{LQ}$ & - \\
\hline & 5.0 & 5.8 & 116.0 \\
\hline & 10.0 & 11.3 & 113.0 \\
\hline \multirow{3}{*}{ Spinach } & 0.0 & $<\mathrm{LQ}$ & - \\
\hline & 5.0 & 4.7 & 94.0 \\
\hline & 10.0 & 9.4 & 94.0 \\
\hline \multirow{3}{*}{ Arugula } & 0.0 & $<\mathrm{LQ}$ & - \\
\hline & 5.0 & 5.7 & 114.0 \\
\hline & 10.0 & 10.8 & 108.0 \\
\hline
\end{tabular}

$<\mathrm{LQ}=$ below the limit of quantification.

Table 2. Concentration of nitrate $\left(\mathrm{NO}_{3}^{-}\right)$determined by ion chromatography in different leafy vegetables of conventional cultivars.

\begin{tabular}{ccccc}
\hline & \multicolumn{4}{c}{ Amount of $\mathrm{NO}_{3}^{-}\left(\mathrm{mg} \cdot \mathrm{L}^{-1}\right)$} \\
\hline Sample & Lettuce & Cauliflower & Spinach & Arugula \\
\hline VC1 & $3.48 \pm 0.83$ & $2.87 \pm 0.23$ & $17.20 \pm 0.72$ & $8.61 \pm 0.64$ \\
VC2 & $3.83 \pm 0.52$ & $3.41 \pm 0.31$ & $20.34 \pm 0.98$ & $9.52 \pm 0.33$ \\
VC3 & $4.02 \pm 0.96$ & $2.96 \pm 0.19$ & $18.48 \pm 0.67$ & $9.26 \pm 0.54$ \\
JQ1 & $1.63 \pm 0.40$ & $1.86 \pm 0.12$ & $11.23 \pm 0.35$ & $2.61 \pm 0.22$ \\
JQ2 & $1.54 \pm 0.34$ & $1.65 \pm 0.48$ & $12.63 \pm 0.85$ & $3.04 \pm 0.31$ \\
JQ3 & $1.59 \pm 0.52$ & $2.15 \pm 0.63$ & $12.15 \pm 0.76$ & $2.96 \pm 0.54$ \\
PO1 & $1.19 \pm 0.89$ & $1.55 \pm 0.72$ & $16.38 \pm 0.65$ & $6.73 \pm 0.62$ \\
PO2 & $1.36 \pm 0.12$ & $1.46 \pm 0.65$ & $14.25 \pm 0.86$ & $5.96 \pm 0.71$ \\
PO3 & $2.05 \pm 0.19$ & $1.32 \pm 0.48$ & $16.43 \pm 1.22$ & $6.23 \pm 0.25$ \\
\hline
\end{tabular}


the WHO, the value established as admissible is the daily dose of $3.65 \mathrm{mg}$ of nitrate ion per $\mathrm{kg}$ of body weight [18]. Thus, a person of $70 \mathrm{~kg}$ may consume up to $256.9 \mathrm{mg}$ of $\mathrm{NO}_{3}^{-}$per day.

Therefore, it can be stated that the LOD and LOQ obtained are suitable for the determination of $\mathrm{NO}_{3}^{-}$in leafy vegetable samples since they are smaller than the highest concentration allowed by the WHO.

It is observed that the lettuce samples collected in the city of Vitória of the Conquista (VC samples) presented higher concentration of $\mathrm{NO}_{3}^{-}$compared to the samples acquired in the cities of Jequié (JQ) and Poções (PO). However, even so, the samples collected in Vitória da Conquista can be consumed without danger of causing damage to health. The difference in nitrate concentration in the different vegetables is due to the geographical region, the particular season of harvest, the choice of cultivar, the use of nitrogen-containing fertilizers, growing conditions, light and humidity [19].

The results obtained using ion chromatography were compared with the ion-selective electrode method (ISE), and the relative differences between the results of the two techniques were presented, as shown in Table 3.

The results obtained with the two techniques were evaluated using the tests of significance $t$-paired student and $\mathrm{F}$. The concentration values determined for the test $\mathrm{F}$ revealed that the samples analyzed presented similar standard deviation for the two evaluated methods. In this way, it is possible to conclude that there is no significant difference between the precision of the methods, at the level of $5 \%$. The influence of determined errors was evaluated by applying the paired Student t-test, considering the results obtained using the ion-selective electrode method as true. The calculated value of $t$ for leafy vegetable samples indicated that the methods do not differ significantly from one another when employed for this type of matrix.

\section{Conclusion}

The analytical method proposed for identification and determination of nitrate in leafy vegetables was simple, fast and accurate. The procedure performed for the treatment of the sample showed good recovery results, besides having the advantage of not using organic solvents. The method provided good linearity,

Table 3. Concentration of nitrate $\left(\mathrm{NO}_{3}^{-}\right)$determined by ion chromatography in different leafy vegetables of conventional cultivars.

\begin{tabular}{ccc}
\hline & \multicolumn{2}{c}{ Amount of $\mathrm{NO}_{3}^{-}\left(\mathrm{mg} \cdot \mathrm{L}^{-1}\right)$} \\
\hline Sample & Ion chromatography & Ion-selective electrode \\
\hline Lettuce 1 & $3.48 \pm 0.83$ & $3.23 \pm 0.67$ \\
Cauliflower 1 & $2.87 \pm 0.23$ & $2.41 \pm 0.19$ \\
Spinach 1 & $17.20 \pm 0.72$ & $16.92 \pm 1.32$ \\
Arugula 1 & $8.61 \pm 0.64$ & $8.38 \pm 0.69$ \\
\hline
\end{tabular}


with limits of detection and quantification that revealed sufficient sensitivity for the determination of $\mathrm{NO}_{3}^{-}$in hardwood vegetables. The anion exchange column in conjunction with suppressed conductivity detection provided a selective determination without interference from the matrix components present in the plants. As perspectives for this study are the application of the method in analyses of various foods, beverages, pesticides, environmental samples and biological fluids.

\section{Conflicts of Interest}

The authors declare no conflicts of interest regarding the publication of this paper.

\section{References}

[1] Salehzadeh, H., Maleki, A., Rezaee, R., Behzad, S. and Ponnet, K. (2020) The Nitrate Content of Fresh and Cooked Vegetables and Their Health-Related Risks. PLoS One, 15, e0227551. https://doi.org/10.1371/journal.pone.0227551

[2] Nuñez, G.M.T., Osburn, W.N., Hardin, M.D., Longnecker, M.G., Harsha, K., Bryan, N.S. and Keeton, J.T. (2015) A Survey of Nitrate and Nitrite Concentrations in Conventional and Organic-Labeled Raw Vegetables at Retail. Journal of Food Science, 80, 942-949. https://doi.org/10.1111/1750-3841.12858

[3] Campanella, B., Onor, M. and Pagliano E. (2017) Rapid Determination of Nitrate in Vegetables by Gas Chromatography Mass Spectrometry. Analytica Chimica Acta, 980, 33-40. https://doi.org/10.1016/j.aca.2017.04.053

[4] Clemente, F.M.V.T. and Haber, L.L. (2012) Horta em pequenos espaços. Técnicas, Brasília.

[5] Bourn, D. and Prescott, J. (2002) A Comparison of the Nutritional Value, Sensory Qualities, and Food Safety of Organically and Conventionally Produced Foods. Critical Reviews in Science and Nutrition, 42, 1-34. https://doi.org/10.1080/10408690290825439

[6] Badar, A., Bamosa, A., Salahuddin, M. and Meheithif, A. (2019) Effect of Zamzam Water on Blood Methemoglobin Level in Young Rats. Journal of Family and Community Medicine, 26, 30-35. https://doi.org/10.4103/jfcm.JFCM_21_18

[7] Morris, M.P. and Gonzáles-Más, A. (1958) Nitrate in Plant Materials, Simple Colorimetric Method for the Determination of Nitrates in Forage Crops. Journal of Agricultural and Food Chemistry, 6, 456-457. https://doi.org/10.1021/jf60088a004

[8] Chetty, A.A. and Prasad, S. (2017) Flow Injection Analysis of Nitrate and Nitrite in Commercial Baby Foods. Food Chemistry, 197, 503-508.

https://doi.org/10.1016/j.foodchem.2015.10.079

[9] Pietrzak, K., Wardak, C. and Lyszczek, R. (2020) Solid Contact Nitrate Ion-Selective Electrode Based on Cobalt(II) Complex with 4,7-Diphenyl-1,10-phenanthroline. Electroanalysis, 32, 724-731. https://doi.org/10.1002/elan.201900462

[10] Lee, C., Araujo, R.C., Koenig, K.M. and Beauchemin, K.A. (2017) Effects of Encapsulated Nitrate on Growth Performance, Carcass Characteristics, Nitrate Residues in Tissues, and Enteric Methane Emissions in Feedlot Beef Steers: Finishing Phase. Journal of Animal Science, 95, 3712-3726. https://doi.org/10.2527/asasann.2017.580

[11] Öztekin, N., Nutku, M.S. and Erim, F.B. (2002) Simultaneous Determination of Nitrite and Nitrate in Meat Products and Vegetables by Capillary Electrophoresis. 
Food Chemistry, 76, 103-106. https://doi.org/10.1016/S0308-8146(01)00287-4

[12] Peres-Olmos, R., Herrero, R., Lima, J.L.F.C. and Montenegro, M.C.B.S.M. (1997) Sequential Potentiometric Determination of Chloride and Nitrate in Meat Products. Food Chemistry, 59, 305-311. https://doi.org/10.1016/S0308-8146(96)00263-4

[13] Perez, M.L.A., Nodarse, I.C. and Mehrdad, Y.P. (2004) Construction of a Polymeric Liquid-Membrane Ion-Selective Electrode (ise) and Its Application for Determination of Nitrate in Tomatoes. Journal of the Chilean Chemical Society, 49, 31. https://doi.org/10.4067/S0717-97072004000100006

[14] Pagliano, E. and Mester, Z. (2019) Determination of Elevated Levels of Nitrate in Vegetable Powders by High-Precision Isotope Dilution GC-MS. Food Chemistry, 286, 710-714. https://doi.org/10.1016/j.foodchem.2019.02.048

[15] Smolders, E., Van, D.M. and Merckx, R. (1990) Simultaneous Determination of Extractable Sulphate and Malate in Plant Extracts Using Ion Chromatography. Journal of Chromatography $A, 514,371-376$. https://doi.org/10.1016/S0021-9673(01)89412-7

[16] Stavroulakis, G., Kafouris, D., Christofidou, M., Paikousis, L., Christou, E., Christodoulidou, M., Kanari, P. and Ioannou-Kakouri, E. (2018) Occurrence of Nitrate in Vegetables and Dietary Exposure Assessment for the Cypriot Adolescent Consumers. Accreditation and Quality Assurance, 23, 115-122. https://doi.org/10.1007/s00769-018-1311-2

[17] ANVISA. Agencia Nacional de Vigilância Sanitária (2010) Farmacopéia Brasileira. 5th Edition, Brasilia.

[18] World Health Organization (2011) Guidelines for Drinking-Water Quality: 3rd Edition, Incorporating 1st and 2nd Addenda, Vol. 1, Recommendations. WHO, Geneva.

[19] Ahn, J., Ho, J.K. and Hahn, J.H. (2015) Standard Addition/Absorption Detection Microfluidic System for Salt Error-Free Nitrite Determination. Analytica Chimica Acta, 886, 114-122. https://doi.org/10.1016/j.aca.2015.06.009 